\title{
Plant Protein Interactions studied by AFM Force Spectroscopy: Nanomechanical and Adhesion properties
}

\author{
Ahmad Fahs* ${ }^{1,3}$, Guy Louarn ${ }^{2}$ \\ ${ }^{1}$ U.R. 1268 Biopolymères Interactions Assemblages (BIA), INRA, Rue de la Géraudière, 44316 \\ Nantes, France. \\ ${ }^{2}$ Institut des Matériaux Jean Rouxel (CNRS - Université de Nantes), 2 Rue de la Houssinière, \\ 44322 Nantes, France. \\ ${ }^{3}$ Present address: Laboratoire des Matériaux Polymères Interfaces Environnement Marin \\ (MAPIEM), Avenue Georges Pompidou, 83162 La Valette du Var, France. \\ * Corresponding author: Dr. Ahmad Fahs \\ E-mail address: ahmad.fahs@yahoo.com
}




\section{ABSTRACT}

The present work was focused on the nanomechanical and adhesion properties of the napin (2S albumin) and cruciferin (12S globulin) rapeseed (Brassica napus L.) proteins, respectively a low and high molecular weight seed protein. Using chemically modified AFM tips, force spectroscopy experiments demonstrated notable differences of the tip-protein interaction strength in regard to the nature of the protein and $\mathrm{pH}$ of the aqueous environment. The results clearly underline the interplay of residence time and electrostatic interactions in the protein-protein adhesion force. Although the nanomechanical experiments concerned more than single molecule, unfolding length and force characteristics of the rapeseed proteins have been statistically found to be sensitive to the structural properties of the protein. This study provides insight into the characterization of rapeseed proteins and then a better knowledge of their interaction and assembling at the nanoscale range.

\section{KEYWORDS}

AFM; Force spectroscopy; Adhesion; Unfolding force and length, Rapeseed proteins. 


\section{INTRODUCTION}

Rapeseed is one of the leading oilseed crops cultivated in the world, ranking fourth with respect to oil production after soybean, palm, and cottonseed. ${ }^{1}$ It is rich in protein and constitutes a good potential source for human nutrition. ${ }^{2}$ Hence, rapeseed proteins have industrial interests in food production and nutritional quality improvement, due to its functional properties ${ }^{3,4}$ (oil adsorption ability, emulsifying and foaming capacities, and stability) and as adhesive in the wood industry, especially in the manufacture of particle board. ${ }^{5}$ They are also of particular interest as green surfactants for food and non-food applications, their functional properties may be adjusted by chemical modification. ${ }^{6}$ Rapeseed contains two predominant proteins which contribute significantly to the functional properties of the seed. ${ }^{7}$ These two proteins are the neutral highmolecular weight cruciferin (12S globulin) and the basic low-molecular weight napin (2S albumin). ${ }^{8}$

Napin consists of two polypeptide chains related by disulfide bonds: a small one $(4,500 \mathrm{Da})$ and a large one (10,000 Da) (Figure 1.a). Napin is a highly basic protein with isoelectric point (iep) superior to 10.0. About its secondary structure, napin is formed by a high content of helix conformation (40-45\%) and a low content of $\beta$-sheet conformation (16-20\%). ${ }^{8-10}$ Two cysteines are present in the small chain and six cysteines in the large chain. The two cysteines in the shortchain are involved in disulfide bonds, linking the chains together, while intrachain disulfide bridges are present in the large chain. ${ }^{8,10}$ Cruciferin is a high molecular weight protein built up of 6 subunits that form a quaternary structure which can be approximated by the model of a trigonal antiprism of the procruciferin 11S analogous (Figure 1.b). Each subunit is composed by a larger and a smaller polypeptide chains linked by disulfide bonds. The molecular weight of the cruciferin is around $300,000 \mathrm{Da}$ and the protein contains 4 polypeptide chains differing by their molecular weights (respectively of around 18,500 $\mathrm{Da}, 21,100 \mathrm{Da}, 26,800 \mathrm{Da}, 31,200 \mathrm{Da}$ 
according to SDS-electrophoresis experiments). The cruciferin is characterized by a low content of helix and a relatively high content of $\beta$-sheet conformation. ${ }^{11-13}$ The ratio of acid to basic amino acid residues is 1.0 , the iep is $7.2,{ }^{14}$ and the radius of gyration of the cruciferin, determined by $\mathrm{X}$-ray scattering, is $4.1 \mathrm{~nm} .^{15}$

Other physicochemical properties for these plant proteins such as aggregation morphology, adhesion and nanomechanical properties have not been yet studied in depth. At the nanoscale, atomic force microscopy (AFM) has been a useful tool for imaging the protein and the polysaccharide aggregations. ${ }^{16,17}$ Due to remarkable technological progress and development of liquid cells and force/volume analysis modes, AFM microscopy is now considered as an adequate technique to assess structure and properties of biopolymers from renewable resources, as milk and food proteins. ${ }^{18,19}$ So, AFM can be used for contributing to the understanding of the functional and nutritional properties of food products, because the physical and chemical properties of proteins can be investigated in a controlled aqueous environment. This may be achieved by using a liquid-cell and therefore by changing $\mathrm{pH}$, temperature, ionic force or adding various additives.

In addition to the high spatial resolution in imaging mode, AFM force spectroscopy mode has been used to study the protein interaction forces, ${ }^{20}$ the polysaccharide-protein interactions, ${ }^{21}$ to detect the contour length of proteins, ${ }^{22}$ and to evaluate their nanomechanical properties through the single molecule force spectroscopy methods. ${ }^{23}$ Mechanical unfolding of single proteins constitutes one of the most exciting AFM experiments. Indeed, the protein can be mechanically stretched between the tip and the solid surface, leading to a consecutive unfolding of the threedimensional structure. Such a typical study was done with titin, the protein responsible for the passive elasticity of muscle. ${ }^{24-28}$ Force-displacement curves showed periodic peaks which attributed to the reversible unfolding transitions of the individual domains of titin. They are 
related the distance between periodic peaks obtained from force curves (25 to $28 \mathrm{~nm}$ ) to the expected length of unfold single immunoglobulin (Ig) domains (theoretical length). The force required ranged from 150-300 $\mathrm{pN}$ and clearly depended on the pulling speed during the retract cycle. Concerning food proteins such as $\beta$-lactoglobulin, one of the most abundant proteins in the milk, nanomechanical properties have put in evidence that the distribution of unfolding length (ranging from $50 \mathrm{~nm}$ to $120 \mathrm{~nm}$ ) depends on the experimental conditions in which the forcedisplacement curves have been recorded, and on the conformational changes of the protein. ${ }^{23}$ However, the studies of the protein-surfaces or protein-protein interactions have put in light the importance to control the surface chemistry of the AFM tip surface with a high degree of precision. $^{29}$

The protein unfolding process concerns the inter- and intra-molecular forces resulting from the interactions between the functional groups of the amino-acid residues. In the present paper, we study the molecular interactions into plant rapeseed proteins and describe their nanomechanical properties using AFM force spectroscopy. We aim to present how these rapeseed proteins can be fixed and aggregated on a solid support (gold surface), in order to study their interactions with chemically modified AFM tips, as well as the interaction forces between proteins. The relation between the structural properties of each protein and the results obtained from the mechanical unfolding experiments will be compared and discussed. 


\section{MATERIALS AND METHODS}

\section{Materials}

Aminopropyl-triethoxysilane APTES (98\%), hexadecyltrimethoxysilane HDTMS (85\%), 11mercaptoundecanoic acid (99\%), N-Ethyl-N'-(3-dimethylaminopropyl)carbodiimide hydrochloride (EDC) (98\%), N-hydroxysuccinimide (NHS) (98\%), absolute ethanol, toluene, sulfuric acid $\mathrm{H}_{2} \mathrm{SO}_{4}(98 \%)$, hydrogen peroxide (30\%), and chrome (99.5\%) were purchased from Sigma-Aldrich (France). Phosphate buffer solution PBS (pH 7.0) and glycine/HCl buffer solution (pH 3.0) were obtained from Fisher-scientific (France), and gold (99.95\%) from Goodfellow (France).

\section{Rapeseed proteins}

Rapeseed cruciferin and napin solutions were prepared from lyophilized powders extracted and highly purified at the "Plant Purified laboratory" facilities of the INRA BIA research unit (Nantes, France). Aqueous solutions were prepared with a concentration of $25 \mu \mathrm{g} / \mathrm{mL}$ or 500 $\mu \mathrm{g} / \mathrm{mL}$ in phosphate buffer (PBS) at $\mathrm{pH}$ 7.0. The water used was distilled through a Milli-Qwater purification system (Millipore Corporation, France).

\section{Preparation of the gold-coated supports}

Gold-coated supports were prepared by physical vapor deposition (PVD) of gold metal on silicon wafers. Firstly, the wafers were cleaned by sequential sonication in absolute ethanol (10 min) and in deionized water $(10 \mathrm{~min})$. Silicon surfaces were treated by a Piranha solution (70/30 $\mathrm{H}_{2} \mathrm{SO}_{4} / \mathrm{H}_{2} \mathrm{O}_{2}$ ) at $80^{\circ} \mathrm{C}$ for 20 min to remove organic contaminants and produce hydroxyl groups, and washed several times in water (caution: Piranha solution is highly corrosive and should be handled with extreme care). The metal sputtering was realized in a vacuum evaporating system 
(Alcatel) operating with a vacuum higher than $10^{-6} \mathrm{mbar}$. Si wafer were successively coated with thin layers of chromium $(15 \mathrm{~nm})$ and gold $(100 \mathrm{~nm})$ with a deposition rate maintained at $\sim 1 \AA / \mathrm{s}$. The roughness of gold layer was verified by AFM.

\section{Immobilization of the proteins on gold surfaces}

Gold-coated substrates were incubated overnight at ambient temperature in napin or cruciferin solutions at a concentration of $25 \mu \mathrm{g} / \mathrm{mL}$ or $500 \mu \mathrm{g} / \mathrm{mL}$. The supports were then rinsed thoroughly with PBS solution and immediately used for AFM analysis.

\section{Chemical modification of the AFM tips with hydrophilic or hydrophobic layers}

Tips were chemically modified to apply a hydrophobic or hydrophilic surface layer. Rectangular $\mathrm{Si}_{3} \mathrm{~N}_{4}$ cantilevers with pyramidal tip (ORC8, Bruker AFM probes) and nominal spring constant of $0.05 \mathrm{~N} / \mathrm{m}$ were used for force measurements (nominal tip radius is $15 \mathrm{~nm}$ ). Prior to silanization, the cantilevers were treated with a standard piranha solution $\left(\mathrm{H}_{2} \mathrm{SO}_{4} / \mathrm{H}_{2} \mathrm{O}_{2}\right)$ for 15 min to remove any contaminants. Tips were carefully rinsed with deionized water and dried with a gentle air flow. The hydrophilic and hydrophobic layers on the tips were obtained by incubating for $2 \mathrm{~h}$ the activated cantilevers in respectively, APTES solution $(5 \mathrm{mM})$ in toluene, and HDTMS solution (5 $\mathrm{mM})$ in absolute ethanol. Finally, the modified cantilevers were rinsed by the corresponding solvent to remove unbound molecules. ${ }^{29}$

\section{Immobilization of the proteins on AFM tips}

In this case, we used gold coated-tips (PNP, NanoWorld) which have triangular shape of cantilever with pyramidal tip and a nominal spring constant of $0.08 \mathrm{~N} / \mathrm{m}$ (nominal tip radius is 10 $\mathrm{nm})$. Before use, gold-coated cantilevers were cleaned for $10 \mathrm{~min}$ by UV-ozone treatment, rinsed 
with ethanol, and dried with a gentle air flow. Firstly, chemical modification of the cleaned tips was performed by incubating the tips in $5 \mathrm{mM}$ of 11 -mercaptoundecanoic acid $\left[\mathrm{HS}-\left(\mathrm{CH}_{2}\right)_{10^{-}}\right.$ $\mathrm{COOH}]$ in absolute ethanol for $6 \mathrm{~h}$ as described elsewhere. ${ }^{30,31}$ The modified tips were rinsed with absolute ethanol and incubated in a solution of EDC/NHS for $1 \mathrm{~h}$. The EDC/NHS solution was prepared in cold PBS, the concentration of both EDC and NHS in the final solution is 5 $\mathrm{mM}^{32,33}$ The AFM tips were thereafter incubated overnight in protein solution $(25 \mu \mathrm{g} / \mathrm{mL})$. Before use, the tips were rinsed with PBS. Attachment of proteins on the tip has been checked by realizing force spectroscopy experiments on freshly gold surface. The presence of interaction signals on the force curves gives an indication of tip functionalization.

\section{Protein-protein adhesion force measurement and protein unfolding experiments}

These experiments were carried out using the gold tips grafted with napin and cruciferin as described just before.

Napin-napin or cruciferin-cruciferin adhesion forces were measured using a tip grafted with napin or cruciferin on a gold surface coated with, respectively, napin or cruciferin. For that, the gold surfaces were previously incubated in a solution of protein at a concentration of $500 \mu \mathrm{g} / \mathrm{mL}$. Experiments were done in PBS buffer ( $\mathrm{pH}$ 7.0) at a pulling speed of $4 \mu \mathrm{m} / \mathrm{s}$ with different tipsurface contact times. To estimate the effect of the ionic strength on the adhesion force intensity, the measurements were performed at a fixed contact time of $5 \mathrm{~s}$, in the presence of various concentration of $\mathrm{NaCl}$.

Unfolding experiments were also done in PBS buffer ( $\mathrm{pH} 7.0)$ by recording force-displacement curves using a tip previously grafted with napin or cruciferin in contact with a freshly gold surface. For these experiments, the pulling speed and the contact time were respectively fixed at 4 $\mu \mathrm{m} / \mathrm{s}$ and $5 \mathrm{~s}$. 


\section{AFM and force spectroscopy}

An AFM microscope (JPK instruments, NanoWizard, Berlin, Germany) was used for imaging and force spectroscopy measurements. AFM images and forces-displacement curves were obtained by using the contact mode AFM in buffer solution using a JPK liquid cell. Interactions forces were calculated following Hooke's low: $F=K c . \Delta z$ where $K c(N / m)$ is cantilever spring constant and $\Delta \mathrm{z}(\mathrm{nm})$ is cantilever deflection (Bending of the cantilever from its equilibrium position). Thermal noise method was used to determine the spring constant of cantilevers. ${ }^{34}$ Calibration was performed in PBS solution over a piece of freshly silicon substrate at room temperature $\left(25^{\circ} \mathrm{C}\right)$, and the maximal loading force was about $1 \mathrm{nN}$. Force curves were taken at different locations on the surface, in order to account for any heterogeneity in the coverage of the protein. AFM data were analyzed by the software SPM Image Processing v.3 from JPK Instruments, to extract the surface roughness, the adhesion forces and the unfolding characteristics (length and force) of rapeseed proteins.

\section{RESULTS AND DISCUSSION}

\section{Immobilization of $2 \mathrm{~S}$ and $12 \mathrm{~S}$ rapeseed proteins on gold surfaces}

The stability of proteins adsorption on a solid support is a key feature that has to be ensured before AFM force spectroscopy experiments. To measure pure adhesion forces between functionalized tips and proteins, the protein-support adhesion has to be higher than tip-protein adhesion. If not, irregular detachment of proteins from their support will add a contribution related only to the characteristics of the support. The presence of thiol functionalities and of disulfide bonds into the structure of napin and cruciferin guided us towards gold surfaces as protein supports. In order to assess the efficiency of the immobilization of napin and cruciferin on gold, we recorded AFM images of the gold coated substrates, before and after adhesion of the 
protein (Figure 2). The freshly native gold surface is smooth and homogeneous (Figure 2.a). The average surface roughness $(\mathrm{Ra})$ was found to be $0.86 \mathrm{~nm}$. Higher magnification AFM view (image not shown) reveals that gold surface is composed of small grains having a characteristic size of $30 \pm 5 \mathrm{~nm}$ in accordance with the literature for similar deposition process. ${ }^{30}$ After incubation in protein solutions and rinsing with PBS, the gold substrates showed a clear modification of surface topography. Figures 2.b and 2.c present AFM images acquired in PBS buffer solution, and plant protein aggregates on gold surface were clearly identified. Although the contact mode AFM had been used, no damage of the protein surfaces has been noticed because the applied force between tip and surface was carefully monitored. The proteins were presumed to be immobilized on gold by chemisorptions via the formation of stable gold-thiol bonds. ${ }^{35}$ However, the analysis of these images (Figures 2.b and 2.c) reveals the presence of more or less small aggregates with a diameter ranging from $200 \mathrm{~nm}$ to $300 \mathrm{~nm}$ for napin and from $300 \mathrm{~nm}$ to $500 \mathrm{~nm}$ for cruciferin. Their thickness is about $10 \mathrm{~nm}$ for napin and $15 \mathrm{~nm}$ for cruciferin. A notable difference in the size of the aggregates was systematically found between these two

proteins which can be related to the difference of their size and to their mobility. ${ }^{14}$ The proteins were adsorbed with a globular shape and with a higher diameter relatively to their radius of gyration (2.5 $\mathrm{nm}$ for napin and $4.1 \mathrm{~nm}$ for cruciferin). This means that a high number of molecules co-exist in each aggregate. Finally, the roughness had significantly increased to reach 2.8 and $4.1 \mathrm{~nm}$ for napin and cruciferin respectively.

\section{Adhesive interactions of rapeseed proteins subject to hydrophilic or hydrophobic contacts}

Force-displacement curves have shown adhesive interactions with all the AFM tips. In order to compare the adhesion force of the two rapeseed proteins and avoid the changes in contact area, especially in our case where the napin and cruciferin have a large difference in molecular weight, 
we have realized the force-displacement curves between AFM probes and proteins coated on gold surface. Otherwise, from protein dimensions, an increase in contact area results in higher values of adhesive strength. ${ }^{36,37}$ So, our method differs from previous studies where the adhesion forces were measured between protein-coated tips and various surfaces. ${ }^{38,39}$

During the approach phase of the force-displacement curves, no abrupt peak has been observed (data not shown), indicating the absence of attractive forces between the AFM tips and the proteins. In contrast, a high peak force at the beginning of retraction phase was illustrated, which is associated with several molecular interactions between the AFM tip and the proteins (Figure 3). This peak is followed by sawtooth pattern due to extension of proteins chains. ${ }^{24,25}$ The measure of the extension force before complete breaking of the contact is usually attributed to the adhesion strength. In order to recognize which factors affect the adhesion, force-displacement curves were recorded with native $\mathrm{Si}_{3} \mathrm{~N}_{4}, \mathrm{NH}_{2}$ and $\mathrm{CH}_{3}$-modified $\mathrm{AFM}$ tips. The measurements were carried out at $\mathrm{pH} 3.0$ and $\mathrm{pH}$ 7.0. Figure 3 present the retraction part of the experimental force-displacement curves measured on napin and cruciferin. Indeed, the adhesion forces clearly decrease when using hydrophobic $\mathrm{CH}_{3}$-modified tips, whereas only minor differences were revealed by means of $\mathrm{Si}_{3} \mathrm{~N}_{4}$ and $\mathrm{NH}_{2}$ - modified tips. For the same protein, the maximal extension $\left(\mathrm{L}_{\text {max }}\right)$ between the tip and surface vary widely for $\mathrm{Si}_{3} \mathrm{~N}_{4}$ and $\mathrm{NH}_{2}$-modified tips. It ranges from $50 \mathrm{~nm}$ to $100 \mathrm{~nm}$ for napin (Figures 3.a and 3.b), and from $100 \mathrm{~nm}$ to $200 \mathrm{~nm}$ for cruciferin (Figures 3.c and 3.d). It may be logically explained because the point of contact was exerted randomly between the hydrophilic tips and the proteins. The proteins are then extended from their different domains, and then a large number of $\mathrm{L}_{\max }$ values are measured. With $\mathrm{CH}_{3}$-modified tips, these values clearly decreased to reach about $50 \mathrm{~nm}$ for napin and cruciferin. These experimental results prove that the hydrophobic character of the $\mathrm{CH}_{3}$ coating decreases significantly the adhesion force between the tip and the rapeseed proteins. These data, extracted from force 
spectroscopy measurements, put in evidence the sensitivity of the nature of the contact with rapeseed proteins on the tip surface chemistry.

In order to complete quantitatively our investigation on the effect of surface chemistry of AFM probes and the adhesion force $\left(\mathrm{F}_{\mathrm{ADH}}\right)$, a statistical treatment of adhesion peaks has been performed. Figure 4 summarizes the magnitude of adhesion force $(\mathrm{pN})$ for napin and cruciferin obtained with different types of AFM tips. The interaction force measured between the native $\mathrm{Si}_{3} \mathrm{~N}_{4}$ tips and the napin is equal to $214 \pm 38 \mathrm{pN}$ at $\mathrm{pH} 3.0$ and no significant difference is observed at $\mathrm{pH} 7.0(242 \pm 34 \mathrm{pN})$. With the $\mathrm{NH}_{2}$-modified AFM tips, the interaction force significantly decreases to $140 \pm 28 \mathrm{pN}$ at $\mathrm{pH} 3.0$ and $193 \pm 40 \mathrm{pN}$ at $\mathrm{pH} 7.0$, and a $\mathrm{pH}$ effect on adhesion strength can be observed. This evolution can be explained by the variation of the charge of napin as a function of the $\mathrm{pH}$. The iep of napin is higher than 10.0, thus the napin is positively charged at $\mathrm{pH} 3.0$ and $\mathrm{pH}$ 7.0. The amino groups of AFM tips are also positively charged after protonation. So, the increase of positive charge density of napin at $\mathrm{pH} 3.0$ leads to decrease the interaction forces between the $\mathrm{NH}_{2}$-modified tip and the protein. Concerning the cruciferin, interactions strength between native $\mathrm{Si}_{3} \mathrm{~N}_{4}$ tips are equal to $166 \pm 32 \mathrm{pN}$ and $179 \pm 31 \mathrm{pN}$ at $\mathrm{pH}$ 3.0 and $\mathrm{pH} 7.0$ respectively. However, in the case of using $\mathrm{NH}_{2}$-modified AFM tip, the mean adhesion force obtained for cruciferin has increased with $\mathrm{pH}$ (from $161 \pm 26 \mathrm{pN}$ at $\mathrm{pH} 3.0$ to 207 $\pm 34 \mathrm{pN}$ at $\mathrm{pH}$ 7.0). This increase in the interaction forces can be explained by the change of the protein charge. Cruciferin (iep 7.2) possesses a positive charge at $\mathrm{pH} 3.0$ and a neutral charge at $\mathrm{pH}$ 7.0. Interactions strength measured by using $\mathrm{CH}_{3}$-modified tips differs clearly than those measured by native $\mathrm{Si}_{3} \mathrm{~N}_{4}$ and $\mathrm{NH}_{2}$-modified tips. This result has been observed for the two proteins. Adhesion force values are about $100 \pm 22 \mathrm{pN}$ for napin and $68 \pm 17 \mathrm{pN}$ for cruciferin. The hydrophobic character of $\mathrm{CH}_{3}$ groups leads to decrease in the interaction forces with napin and cruciferin. 
Concerning the validity of our results, the values of interaction forces of rapeseed proteins with $\mathrm{NH}_{2}$ functional groups are in the same order of magnitude of that published in the literature for other proteins like BSA and blood plasma proteins. ${ }^{38,39}$ However this is not the case of $\mathrm{CH}_{3}$ groups, adhesion force values of napin and cruciferin appears to be lower of that observed for BSA and blood plasma proteins, which is to be relied to the higher hydrophobicity of BSA, as compared with rapeseed proteins, giving rise to stronger adhesion forces with a hydrophobic tip. ${ }^{38,39}$ We suggest that the hydrophobic interactions does not play a major role and other forces (e.g. electrostatic, van der Waals) are involved in adhesion properties of rapeseed proteins. Indeed, as we will demonstrate in the next section, the electrostatic interactions appear to be the major responsible in adhesion force.

\section{Napin-napin and cruciferin-cruciferin adhesion forces}

The effect of contact time on the adhesion force established between the proteins (napin or cruciferin) grafted on the tip and that immobilized on the gold surface has been studied and presented in figure 5. At low contact time $(0.2 \mathrm{~s})$, adhesion force values were $68 \mathrm{pN}$ for napin and $117 \mathrm{pN}$ for cruciferin. The force required to separate the protein-coated tip from the proteincoated surface increases gradually and reaches three-fold with a contact time of $4 \mathrm{~s}$. A large delay enhances the formation of inter-molecular bonds (hydrogen bonds, electrostatic attraction between groups of opposite charge) that leads to increase the interactions between the proteins. These results suggest that during the approach and the contact between the proteins, molecular rearrangements can occur to allow a more stable conformation. Over relatively long contact time, strong and weak bonds between the two opposing surfaces will be developed. Consequently, the force required to separate the AFM tip from the surface becomes more important. The time range for which the adhesion force reaches a maximal magnitude depends on the material between the 
AFM tip and surface. In the case of rapeseed proteins, maximal interaction between two identical proteins has been reached over $2 \mathrm{~s}$. The same time has been reported by Mondon et al. ${ }^{40}$ who observed the adhesion force between a protein-modified AFM tip and titanium surfaces. So, the increase in adhesion force with contact time is a result of water exclusion, protein rearrangement, and conformation changes in the proteins as well as the formation of hydrogen bonds. ${ }^{41}$ In all the cases, adhesion force values of cruciferin are higher than those of napin. This result can be explained by the fact that the cruciferin possesses a high molecular weight, and the adhesion force depends on the contact area between the AFM tip and the surface. ${ }^{36,37}$

To identify the principal component responsible in adhesion force, we have studied the effect of ionic strength which is adjusted by dissolving $\mathrm{NaCl}$ in the appropriate concentrations. Figure 6 shows the dependence of adhesion force on $\mathrm{NaCl}$ concentration and their values extracted from experimental force curves. From this study, it has been measured that adhesion force of the two proteins decreases with increasing ionic strength. At $\mathrm{pH} 7$, cruciferin (iep 7.2) possesses almost the same number of positively and negatively charged groups, however napin (iep > 10) is positively charged. The magnitude of the electrostatic interactions between the proteins decreased significantly to achieve low adhesion value $(52 \mathrm{pN})$. Despite cruciferin and napin exhibit different characteristics in structure, molecular weight and iep values, the force of adhesion tends to be similar for the higher ionic strength conditions. Dropping to $52 \mathrm{pN}$ in $200 \mathrm{mM} \mathrm{NaCl}$, van der Waals interactions for higher $\mathrm{NaCl}$ concentration may be seen as preponderant by comparison to electrostatic interactions.

The attractive interaction between napin-napin and between cruciferin-cruciferin, resulting from functional groups having opposite charges, becomes progressively lower whereas the ionic strength of the solution increases. The protein surface charges are balanced by a layer of oppositely charged ions from the solution. Thereby, $\mathrm{NaCl}$ binds to the protein, neutralizes its 
dipole moment and reduces protein-protein interactions. This screening effect, where electrostatic interactions are reduced with increasing salt ions concentration (i.e. ionic strength), was described to influence strongly food proteins interaction. ${ }^{42}$ However, it takes here the advantage to prove that electrostatic interaction is preponderant on the inter-protein adhesion of napin and cruciferin. This result fits very well with the study on hydrophobic contact discussed here-before. Also, AFM can be seen as an adequate tool to identify the major contribution of the interactions of plant proteins at the nanoscale. Of note, our experiments have been done in PBS solution, which relatively contains high concentration of $\mathrm{NaCl}(137 \mathrm{mM})$. Therefore, it is possible that the protein-protein interactions could be reduced due to $\mathrm{NaCl}$ pre-exiting in the PBS buffer.

The effect of ionic strength on molecular interactions, investigated by AFM force spectroscopy, has been previously reported by other authors. Vengasandra et al. $^{43}$ reported that the adhesive forces between protein-receptor were remarkably higher $(460 \pm 370 \mathrm{pN})$ in deionized water than in PBS solution $0.01 \mathrm{M}(170 \pm 180 \mathrm{pN})$. Specific interaction between DNA and protein as a function of ionic strength has been also studied by Jiang et al. ${ }^{44}$, who observed a weaker rupture force in the presence of a high $\mathrm{NaCl}$ salt concentration (adhesion force value vary from $154 \pm 20$ $\mathrm{pN}$ in $0.15 \mathrm{M} \mathrm{NaCl}$ to $136 \pm 27 \mathrm{pN}$ in $1.5 \mathrm{M} \mathrm{NaCl}$ ). In the same way, our results are in agreement with those obtained by $\mathrm{Xu}$ et al. ${ }^{41,45}$ They observed a decrease of the adhesion between several proteins (BSA-BSA, BSA-protein A, BSA-lysozyme, BSA-polylysine) with increasing ionic strength. At $\mathrm{pH}$ close to iep of BSA and apoferritin (the case of cruciferin in our study), ValleDelgado et al. ${ }^{46}$ also observed a decrease of adhesion force with $\mathrm{NaCl}$ salt concentration. Conversely, they showed an increase of adhesion force as the salt concentration increases when $\mathrm{pH}$ is far from iep (the case of napin in our study). This observed difference may be explained by a prior effect of $\mathrm{NaCl}$ pre-existing in the buffer, which already screened the repulsive electrostatic interactions between the napin proteins. Beyond a critical concentration of $\mathrm{NaCl}$, the structure of 
napin proteins becomes highly condensed and positively charged, leading to a smaller adhesion strength as observed here.

\section{Unfolding properties of napin and cruciferin}

Classical experimental methods for studying unfolding properties are realized by immobilizing protein macromolecules on surface, approaching AFM tip to and retracting from the sample surface. $^{25,47}$ The goal is to pick up a fraction of protein, extend it by AFM tip and measure the force exerted in extension process. Our method consists in immobilizing the protein on AFM tip, and interact it with a freshly gold surface. Figure 7 shows typical force-displacement curves during retracting the AFM tip from the surface. The observed pattern is due to unfolding of the polypeptide chains. Each peak is attributed to the breakage of a folded structure. The protein is then stretched until the force is sufficient for another part of the folded structure. In general, the distance between two consecutive peaks corresponds to the length of unfolded domain. The value of increase in contour length, resulting from stretching of a single domain, and the value of force needed to unfold such a single domain have been statistically analyzed. The analysis has been realized for 500 unfolding events (Figure 8 and 9).

All Length distributions for napin and cruciferin show that the measured distance between peaks are less than $100 \mathrm{~nm}$. The range of distance appears to be related to the structure of protein. Figure 8.a, corresponding to napin unfolding experiments, reveals a length distribution with two peaks: the first at $16.2 \pm 6.5 \mathrm{~nm}$ and $34.3 \pm 6.6 \mathrm{~nm}$. On the other hand, unfolding experiments of cruciferin show an increase of extension values, and four major distributions can be revealed. Length values are $31.2 \pm 6.6 \mathrm{~nm}, 46.6 \pm 5.1 \mathrm{~nm}, 61.3 \pm 4.4 \mathrm{~nm}$ and $81.3 \pm 7.4 \mathrm{~nm}$ (Figure 8.b). Unfolding events frequency has decreased at long elongation $(81.3 \mathrm{~nm})$. The number of peaks 
may be related to the cruciferin structure, which contains four polypeptide chains having different molecular weights.

Unfolding experiments applied on napin and cruciferin demonstrate the possibility to stretch the internal molecular domains (Figure 8). The expected lengths of unfolded chains were compared with the experimental unfolding lengths obtained by force spectroscopy experiments (Table 1). In the case of napin, the expected length of the small polypeptide chain is about $14 \mathrm{~nm}$ and that of the large one is about $32 \mathrm{~nm}$, considering an elementary length of $0.37 \mathrm{~nm}$ by amino acid. Based on the results obtained in figure 8.a, it is possible that the population characterized by the short unfolding length $(16.2 \pm 6.5 \mathrm{~nm})$ corresponds to the extension of small polypeptide chains, and the population characterized by the long unfolding length $(34.3 \pm 6.6 \mathrm{~nm})$ is attributed to the large chains. In the case of cruciferin, attribution of unfolding lengths and forces populations is complicated. Predicted lengths for cruciferin chains are to be $59 \mathrm{~nm}, 68 \mathrm{~nm}, 86 \mathrm{~nm}$ and $100 \mathrm{~nm}$. Statistical analysis of unfolding lengths displayed four populations at $31.2 \pm 6.6 \mathrm{~nm}, 46.6 \pm 5.1$ $\mathrm{nm}, 61.3 \pm 4.4 \mathrm{~nm}$ and $81.3 \pm 7.4 \mathrm{~nm}$ (Figure 8.b). Based on this result, one can suggest that the cruciferin structure has been partially unfolded, and a large number of polypeptide chains has been not successfully extended.

The statistical analysis of unfolding forces of revealed a magnitude range from few $\mathrm{pN}$ to about $1300 \mathrm{pN}$. Unfolding force distributions associated for napin show two major peaks at $264 \pm 88$ $\mathrm{pN}$ and $497 \pm 65 \mathrm{pN}$ and a minor peak at $693 \pm 40 \mathrm{pN}$ (Figure 9.a). However, analysis of cruciferin unfolding forces provides four peaks at $429 \pm 150 \mathrm{pN}, 675 \pm 68 \mathrm{pN}, 883 \pm 80 \mathrm{pN}$ and $1154 \pm 143 \mathrm{pN}$ (Figure 9.b). The presence of disulfide bonds into proteins creates additional mechanical barriers and limits protein unfolding. ${ }^{48,49}$ Extension process may occur randomly, resulting a variation of the maximum extension of protein. This later has been analyzed by measuring the distance between the beginning of protein extension and the end of force curve 
(detachment of protein from the gold surface). The average values of maximal unfolding lengths $\left(\mathrm{L}_{\max }\right)$ of napin and cruciferin were about $208 \pm 70 \mathrm{~nm}$ and $287 \pm 37 \mathrm{~nm}$ respectively. $\mathrm{L}_{\max }$ values approximately indicate the number of proteins involved in unfolding process. In the case of napin which possesses a small molecular weight $(14,500 \mathrm{Da})$ and 126 amino acids, $\mathrm{L}_{\max }$ of $208 \mathrm{~nm}$ corresponds to 3-6 molecules of napin (calculated length is about $46 \mathrm{~nm}$ by considering the length of one amino acid is $0.37 \mathrm{~nm}$ ). This result demonstrates the presence of several napin proteins on the tip. However it is not the case for cruciferin because a shorter extension of the chains was found (about $280 \mathrm{~nm}$ ). The maximal extension length of one cruciferin protein $(300,000 \mathrm{Da})$ is about $976 \mathrm{~nm}$ (based on the presence of 2637 amino acids). This clearly proves that the cruciferin protein is partially extended for all the experiments. The observed differences between the unfolding behavior of cruciferin and napin chains can be related to their own electrostatic interactions, thiols/disulfide bonds content and/or secondary structure that may all enhance or inhibit various zones of each polypeptide chains. ${ }^{50}$

\section{CONCLUSION}

Plant proteins are an important class of renewable biomaterials that are actively developed for applications in a variety of industrial and food products. Accordingly, the knowledge of the nanomechanics properties became a real challenge. In this work, we have presented an exhaustive study of two important rapeseed (Brassica napus L.) seed proteins, the napin (2S albumin) and cruciferin (12S globulin). Preliminary results obtained by imaging mode AFM showed the capability of napin and cruciferin to be strongly adsorbed on gold-coated surfaces as nanometer sized aggregates. We demonstrated the ability of AFM force spectroscopy to quantitatively measure the magnitude of interactions involved in biopolymer systems. Napin-napin and cruciferin-cruciferin adhesion forces were analyzed and the importance of the residence time 
between themselves and the ionic strength of buffer solution has been put in evidence. Particularly, our study reveals the interplay of electrostatic interactions in adhesion force. Protein unfolding experiments reveal a high sensitivity to the molecular structure. In other words, high structural complexity leads to disrupt the protein unfolding process. But, with a statistic approach, we have been able to determine the main parameters as unfolding force and length distributions of domains. Finally, we put in evidence that AFM technique allows the direct measurement of the biomolecular interactions involved in rapeseed proteins, and the accurate quantification of their adhesion and their unfolding properties. In relation, these experiments look promising for further investigation of specific properties related to plant proteins interaction at the nanometer scale, as for example, the role of the $2 \mathrm{~S}$ albumin proteins in food allergenicity.

\section{ACKNOWLEDGEMENTS}

We thank Dr. Serge Bérot at BIA-INRA for providing highly purified rapeseed proteins. We also thank Dr. Cédric Gaillard, Dr. Olivier Piètrement and Dr. Jacques Guéguen for helpful discussions. This work was supported financially by the Division for Science and Process Engineering of Agricultural Products (CEPIA) of the National Institute of Agronomical Research (INRA). 


\section{REFERENCES}

$1 \mathrm{FAO} / \mathrm{WHO} / \mathrm{UNU}$. Agricultural bulletin board on data collection, dissemination and quality of statistics, World Health Organization, Geneva, 2002.

2 L. Tranchino, R. Constantino and G. Sodini, Qual. Plant Foods Hum. Nutr., 1983, 32, 305.

3 J. M. Chobert, L. Briand, J. Guéguen, Y. Popineau, C. Larré and T. Haertlé, Food/Nahrung, 1996, 40, 177.

4 X. Y. Dong, L. L. Guo, F. Wei, J. F. Li, M. L. Jiang, G. M. Li, Y. D. Zhaoa and H. Chen, J. Sci. Food Agric., 2011, 91, 1488.

5 C. Müller, U. Kües, C. Schöpper and A. Kharazipour, In Wood production, wood technology, and biotechnological impacts, ed. U. Kües, Universitätsverlag Götingen, 2007, p 359.

6 A. Gerbanowski, C. Rabiller and J. Guéguen, J. Colloid Interface Sci., 2003, 262, 391.

7 C. Malabat, Ph.D. Thesis, University of Nantes, France, 2002.

8 S. Bérot, J. P. Compoint, C. Larré, C. Malabat and J. Guéguen, J. Chromatogr. B, 2005, 818, 35.

9 K. D. Schwenke, B. Raab, J. Uhlig, H. Tkocz, J. Behlke, M. Böttger and U. Freimuth, Food/Nahrung, 1973, 17, 791.

10 B. Lönnerdal and J. C. Janson, Biochem. Biophys. Acta., 1972, 278, 175.

11 K. D. Schwenke, B. Raab, P. Plietz and G. Damaschun, Food/Nahrung, 1983, 27, 165.

12 M. Dalgalarrondo, J. M. Robin and J. L. Azanza, Plant Science, 1986, 43, 115.

13 K. D. Schwenke, M. Shultz, K. J. Linow, K. Gast and D. Zirwer, Int. J. Pept. Protein Res., 1980, 16, 12.

14 K. D. Schwenke, Food/Nahrung, 1990, 34, 225.

15 P. Plietz, G. Damaschun, J. J. Müller and K. D. Schwenke, Eur. J. Biochem., 1983, 130, 315. 
16 S. Ikeda and V. Morris, Biomacromolecules, 2002, 3, 382.

17 A. N. Round, N. M. Rigby, A. J. MacDougall and V. Morris, Carbohydr. Res., 2010, 345, 487.

18 A. R. Kirby, A. P. Gunning and V. Morris, Trends Food Sci. Technol., 1995, 6, 359.

19 V. I. Uricanu, M. H. G. Duits and J. Mellema, Langmuir, 2004, 20, 5079.

20 E. L. Florin, V. T. Moy and H. E. Gaub, Science, 1994, 264, 415.

21 E. L. Adams, P. A. Kroon, G. Williamson, H. J. Gilbert and V. Morris, Carbohydr. Res., 2004, 339, 579.

22 M. Carrion-Vasquez, P. E. Marszalek, F. Andres, F. Oberhauser and J. M. Fernandez, Proc. Natl. Acad. Sci. U.S.A., 1999, 96, 11288.

23 A. Touhami and J. R. Dutcher, Soft Matter, 2009, 5, 220.

24 R. Rief, M. Gautel, F. Oesterhelt, J. M. Fernandez and H. E. Gaub, Science, 1997, 276, 1109.

25 L. Tskhovrebova, J. Trinick, J. A. Sleep and R. M. Simmons, Nature, 1997, 387, 308.

26 M. Carrion-Vazquez, A. F. Oberhauser, S. B. Fowler, P. E. Marszale, S. E. Broedel, J. Clarke and J. M. Fernandez, Proc. Natl. Acad. Sci. U.S.A., 1999, 96, 3694.

27 P. E. Marszalek, H. Lu, H. B. Li, M. Carrion-Vazquez, A. F. Oberhauser, K. Schulten and J. M. Fernandez, Nature, 1999, 402, 6757, 100.

28 H. B. Li, W. A. Linke, A. F. Oberhauser, M. Carrion-Vazquez, J. G. Kerkviliet, H. Lu, P. E. Marszalek and J. M. Fernandez, Nature, 2002, 418, 998.

29 D. V. Vezenov, A. Noy, L. F. Rozsnyai and C. M. Lieber, J. Am. Chem. Soc., 1997, 119, 2006.

30 M. Fujihira, Y. Tani, M. Furugori, U. Akiba and Y. Okabe, Ultramicroscopy, 2001, 86, 63.

31 M. A. Poggi, L. A. Bottomley and P. Lillehei, Nano Lett., 2004, 4, 61. 
32 S. Sam, L. Touahir, J. S. Andresa, P. Allongue, J. N. Chazalviel, A. C. Gouget-Laemmel, C. H. de Villeneuve, A. Moraillon, F. Ozanam, N. Gabouze and S. Djebbar, Langmuir, 2010, 26, 809.

33 G. Andre, K. Leenhouts, P. Hols and Y. F. Dufrêne, J. Bacteriol., 2008, 190, 7079.

34 H. J. Butt and M. Jaschke, Nanotechnology, 1995, 6, 1.

35 A. Ulman, Chem. Rev., 1996, 96, 1533.

36 A. Fahs, M. Brogly, S. Bistac and M. Schmitt, Carbohydr. Polym., 2010, 80, 105.

37 O. Piètrement and M. Troyon, J. Colloid Interface Sci., 2000, 226, 166.

38 M. S. Wang, L. B. Palmer, J. D. Schwartz and A. Razatos, Langmuir, 2004, 20, 7753.

39 S. Kidoaki and T. Matsuda, Langmuir, 1999, 15, 7639.

40 M. Mondon, S. Berger and C. Ziegler, Anal. Bioanal. Chem., 2003, 375, 849.

41 L. C. Xu, V. Vadillo-Rodriguez and B. E. Logan, Langmuir, 2005, 21, 7491.

42 N. Mahmoudi, C. Gaillard, F. Boué, M. A. V. Axelos and A. Riaublanc, J. Colloid Interface Sci., 2010, 345, 54.

43 S. Vengasandra, G. Sethumadhavan, F. Yan and R. Wang, Langmuir, 2003, 19, 10940.

44 Y. Jiang, C. Zhu, L. Ling, L. Wan, X. Fang and C. Bai, Anal. Chem., 2003, 75, 2112.

45 L. C. Xu and B. E. Logan, Environ. Sci. Technol., 2005, 39, 3592.

46 J. J. Valle-Delgado, J. A. Molina-Bolívar, F. Galisteo-González, M. J. Gálvez-Ruiz, A. Feiler and M. W. Rutland, Langmuir 2006, 22, 5108.

47 C. McAllister, M. A. Karymov, Y. Kawano, A. Y. Lushnikov, A. Mikheikin, V. Uversky and Y. L. Lyubchenko, J. Mol. Biol., 2005, 354, 1028.

48 S. R. K. Ainavarapu, J. Brujić, H. H. Huang, A. P. Wiita, H. Lu, L. Li, K. A. Walther, M. Carrion-Vazquez, H. Li and J. M. Fernandez, Biophys. J., 2007, 92, 225. 
49 P. Carl, C. H. Kwok, G. Manderson, D. W. Speicher and D. E. Discher, Proc. Natl. Acad. Sci. U.S.A., 2001, 98, 1565.

50 C. M. Dobson, Nature, 2003, 426, 884. 


\section{FIGURE AND TABLE CAPTIONS}

Figure 1. Representation of : (a) the two polypeptide chains of the napin (2S albumin), and (b) the analogous procruciferin $11 \mathrm{~S}$ globulin as a simplified model of the trigonal antiprism cruciferin (12S globulin) for which two 11S trimeric structures as shown here has to be superposed giving the hexameric structure of cruciferin. The cruciferin contains twelve polypeptide chains ((PBD ID cruciferin and PBD ID:1PNB napin).

Figure 2. AFM 3D topographic images $(10 \mu \mathrm{m} \times 10 \mu \mathrm{m})$ of napin and cruciferin acquired in contact mode and taken under PBS solution. The vertical scale bar for all images is $50 \mathrm{~nm}$. (a) Image of freshly gold film evaporated on silicon substrate, (b) and (c) are respectively the images of napin and cruciferin proteins immobilized on gold surface incubated in $25 \mu \mathrm{g} / \mathrm{mL}$ protein solutions.

Figure 3. Experimental force-displacement curves (retraction phase) of napin and cruciferin acquired at $\mathrm{pH} 3(\mathrm{a}, \mathrm{c})$ and $\mathrm{pH} 7(\mathrm{~b}, \mathrm{~d})$. Black curves correspond to the force spectroscopy experiments realized using $\mathrm{Si}_{3} \mathrm{~N}_{4}$ tips, the dark and light gray curves correspond respectively to $\mathrm{NH}_{2}$ - and $\mathrm{CH}_{3}$-modified AFM tips.

Figure 4. Histograms showing the evolution of the intensity of the adhesion force of napin and cruciferin at $\mathrm{pH} 3$ and $\mathrm{pH} 7$ as a function of the surface chemistry of the AFM tips. The contact time between the AFM tip and the surface was fixed at $0.5 \mathrm{~s}$. In each histogram there are 300 measurements. 
Figure 5. Evolution of the napin-napin and cruciferin-cruciferin adhesion forces as a function of the contact time imposed between the proteins. The force curves have been recorded in PBS at a pulling speed of $4 \mu \mathrm{m} / \mathrm{s}$. Each value is the average of 300 adhesion force measurements.

Figure 6. Influence of the $\mathrm{NaCl}$ concentration in the aqueous environment on the napin-napin and cruciferin-cruciferin adhesion force $(\mathrm{pN})$. The force curves have been recorded in PBS at a pulling speed of $4 \mu \mathrm{m} / \mathrm{s}$ and a contact time of $5 \mathrm{~s}$. There are 300 measurements at each value.

Figure 7. Force-extension profiles for napin (a) and cruciferin (b) obtained by force spectroscopy experiments. In the same force-extension profile, the trace shows varying unfolding lengths.

Figure 8. Statistical distributions of the unfolding lengths $\mathrm{L}(\mathrm{nm})$ deduced from the forceextension curves of the napin (a) and cruciferin (b). The force curves have been recorded at a pulling speed of $4 \mu \mathrm{m} / \mathrm{s}$ in PBS buffer solution ( $\mathrm{pH}$ 7.0). The contact time between the AFM tip and the surface was fixed at $5 \mathrm{~s}$. In each histogram there are 500 measurements.

Figure 9. Statistical distributions of the unfolding forces $\mathrm{F}(\mathrm{pN})$ deduced from the forceextension curves of the napin (a) and cruciferin (b). The force curves have been recorded at a pulling speed of $4 \mu \mathrm{m} / \mathrm{s}$ in PBS buffer solution ( $\mathrm{pH}$ 7.0). The contact time between the AFM tip and the surface was fixed at $5 \mathrm{~s}$. In each histogram there are 500 measurements.

Table 1. Comparison between expected and experimental results of unfolded chain lengths of napin and cruciferin. 


\section{FIGURES}

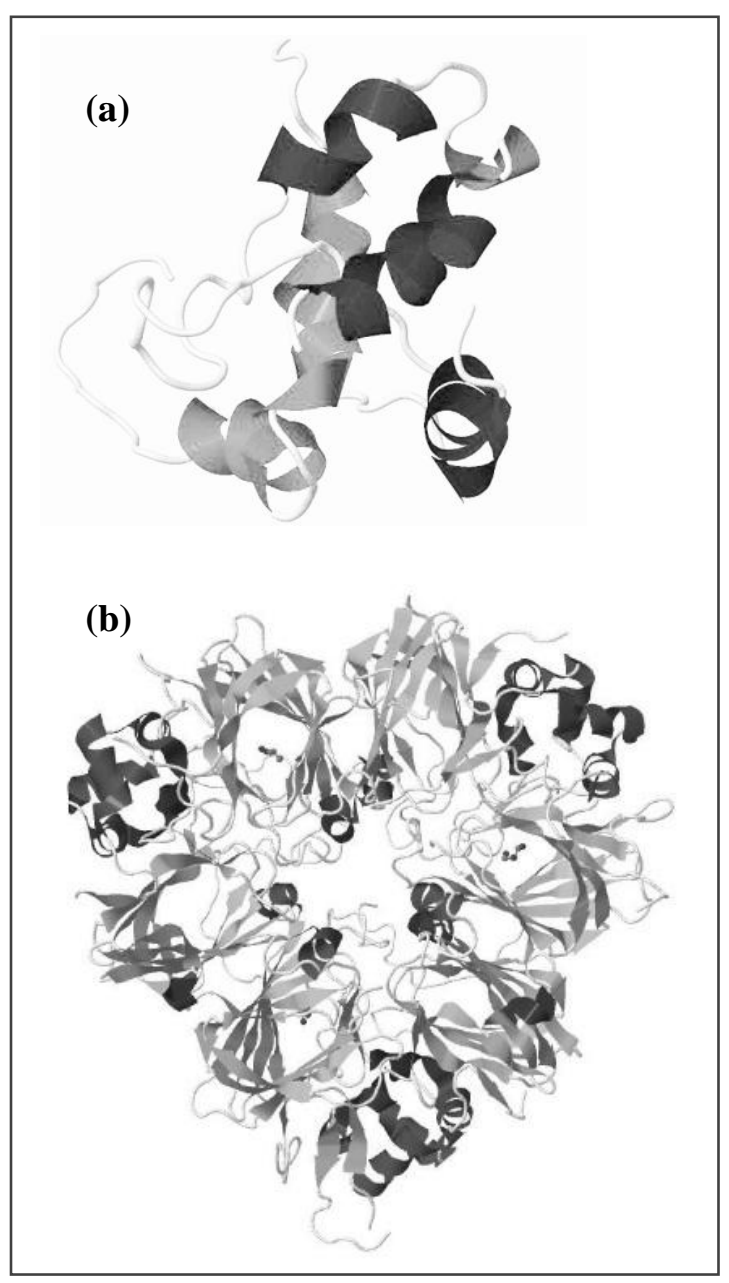

Figure 1. 


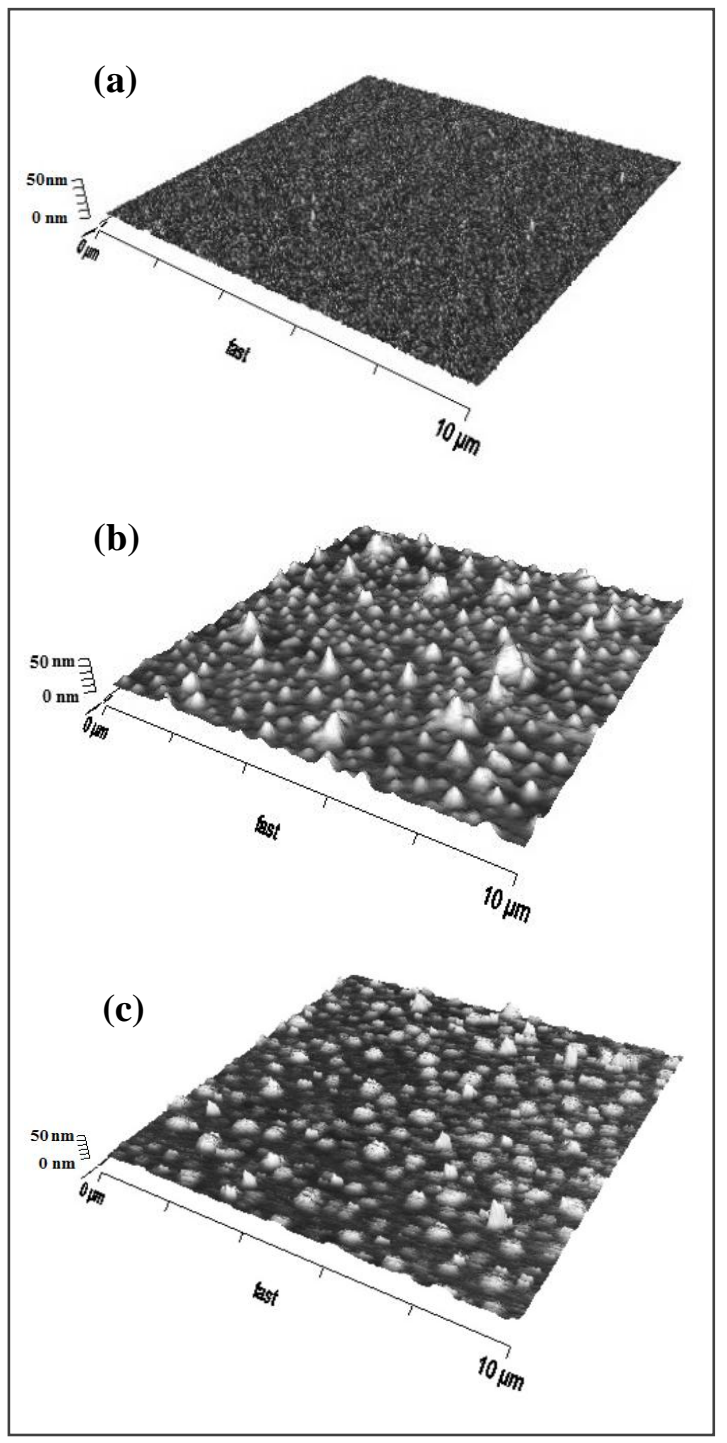

Figure 2. 


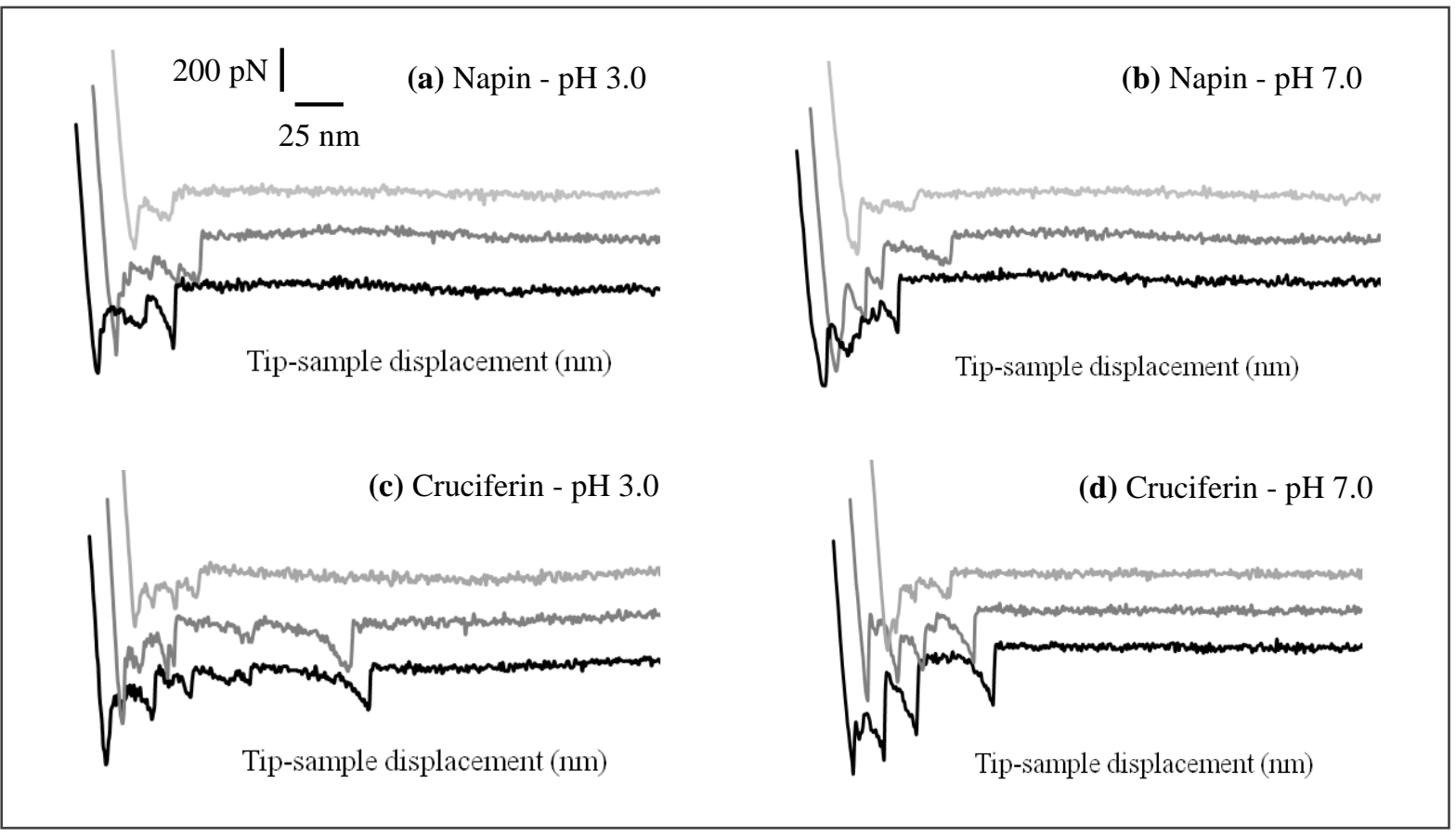

Figure 3. 
Figure 4.

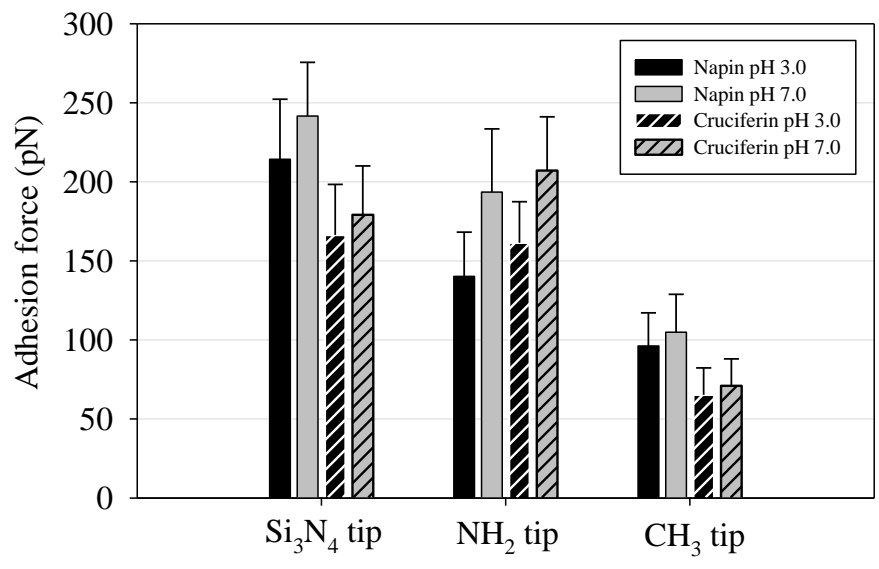




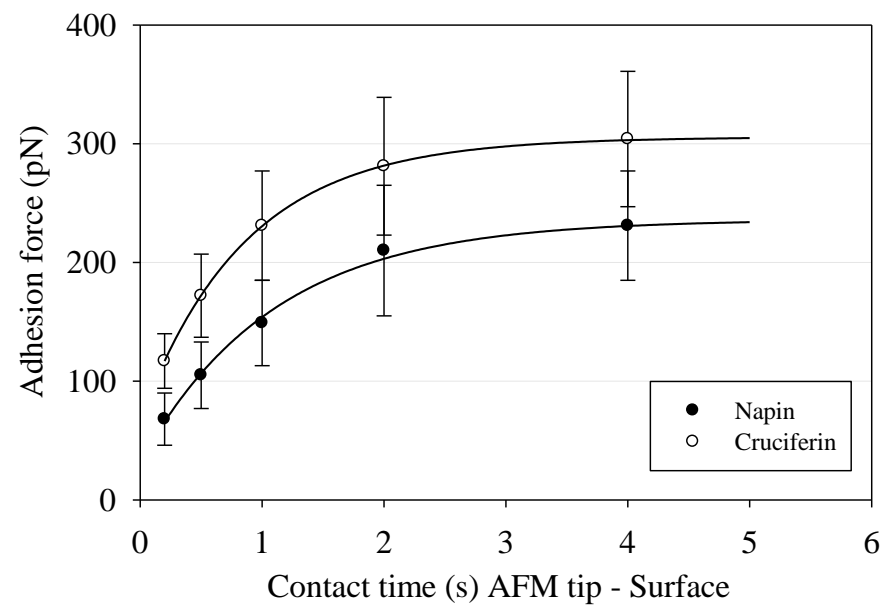

Figure 5. 


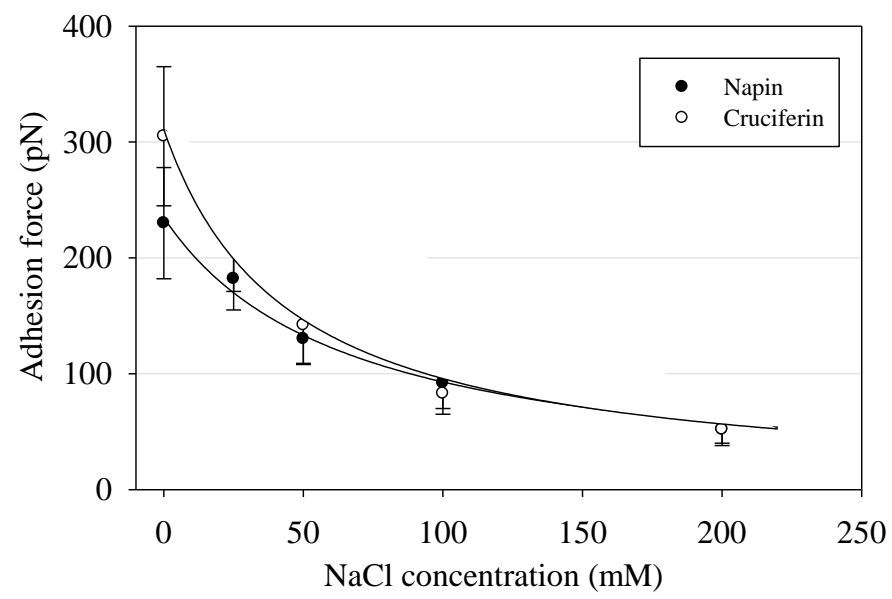

Figure 6. 


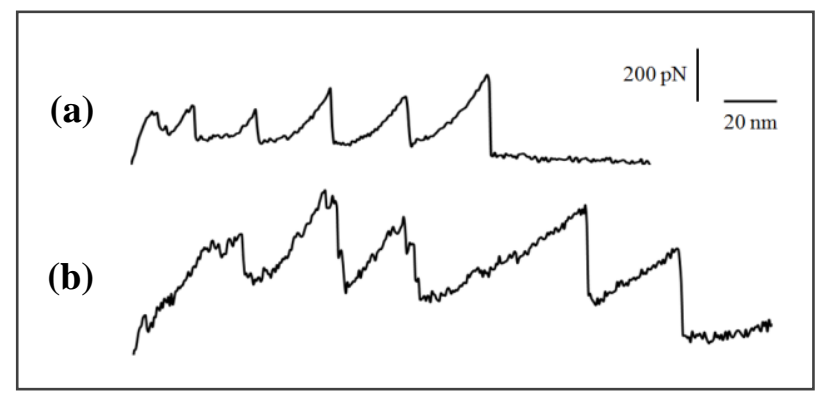

Figure 7. 


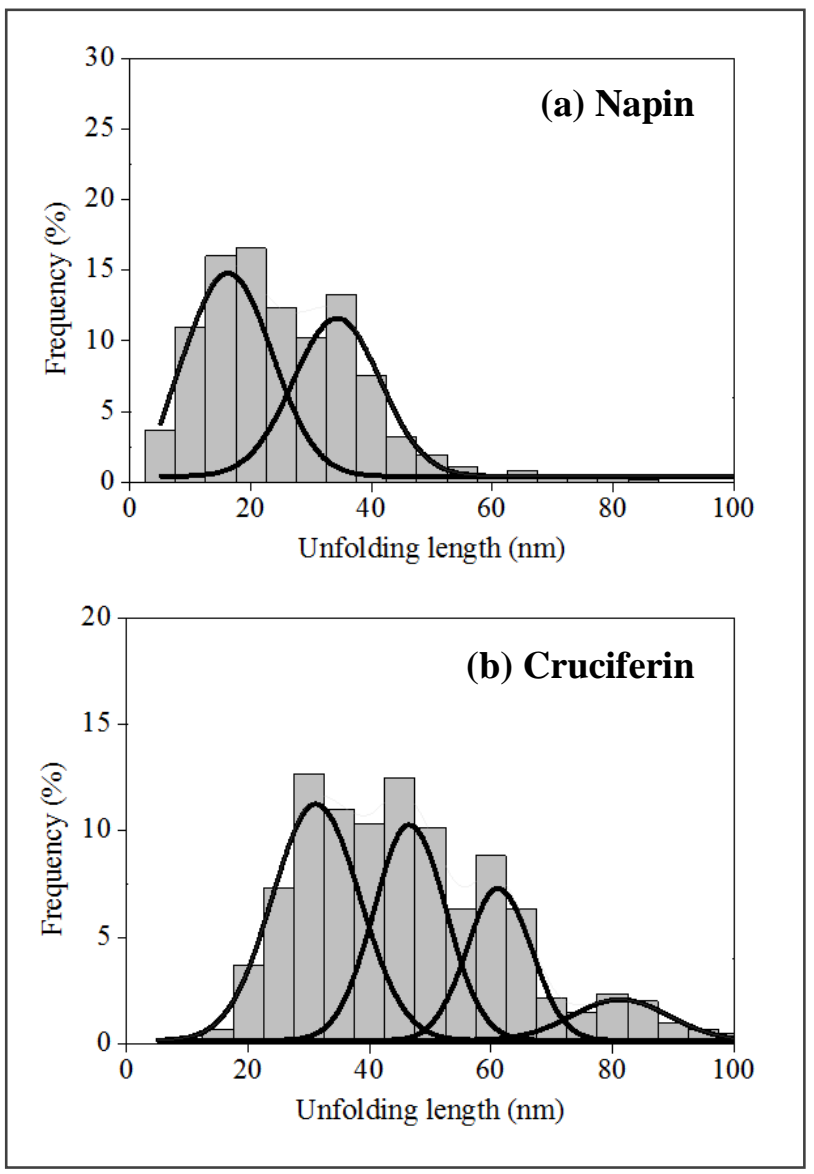

Figure 8. 


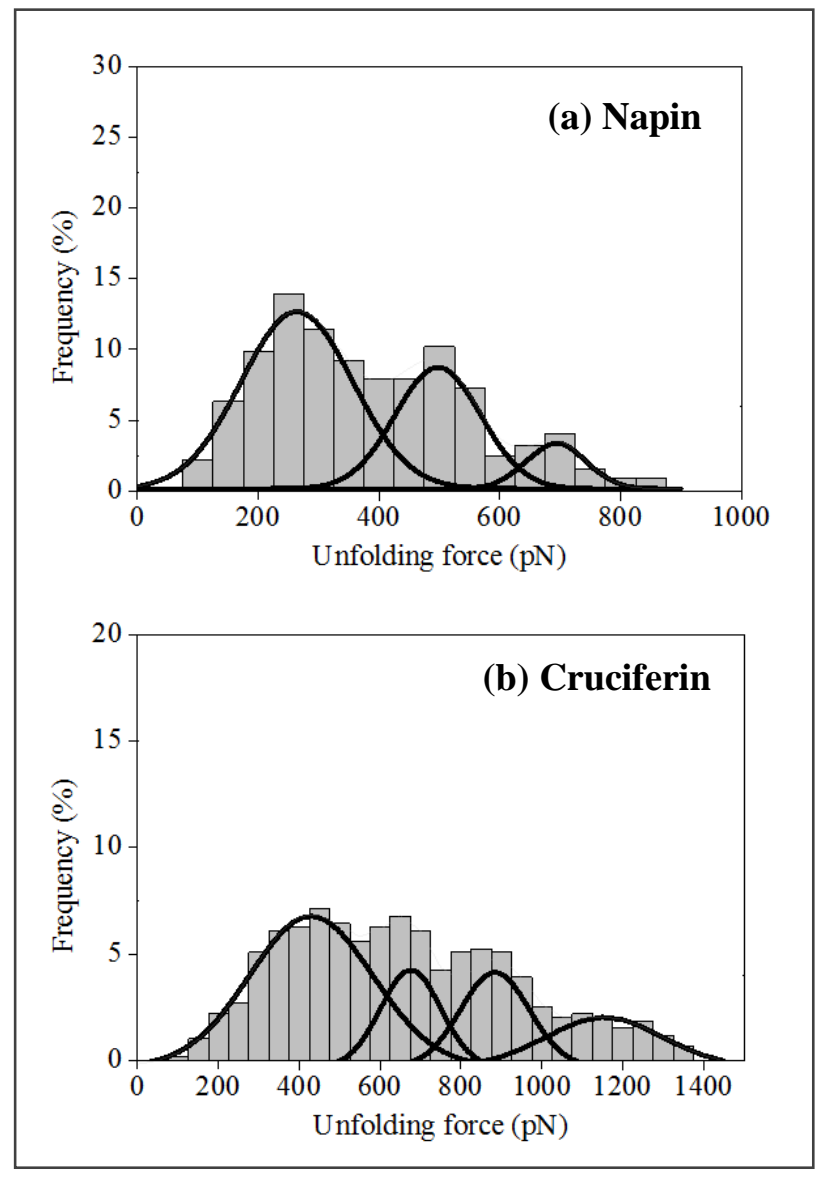

Figure 9. 


\begin{tabular}{cccc}
\hline \multicolumn{2}{c}{ Protein } & Expected length $(\mathrm{nm})$ & Experimental length $(\mathrm{nm})$ \\
\hline \multirow{2}{*}{ Napin } & Chain 1 & 14 & $16.2 \pm 6.5$ \\
\cline { 2 - 4 } & Chain 2 & 32 & $34.3 \pm 6.6$ \\
\hline \multirow{3}{*}{ Cruciferin } & Chain 1 & 59 & $31.2 \pm 6.6$ \\
\cline { 2 - 4 } & Chain 2 & 68 & $46.6 \pm 5.1$ \\
\cline { 2 - 4 } & Chain 3 & 86 & $61.3 \pm 4.4$ \\
\cline { 2 - 4 } & Chain 4 & 100 & $81.3 \pm 7.4$ \\
\hline
\end{tabular}

Table 1. 


\section{TABLE OF CONTENTS ENTRY}

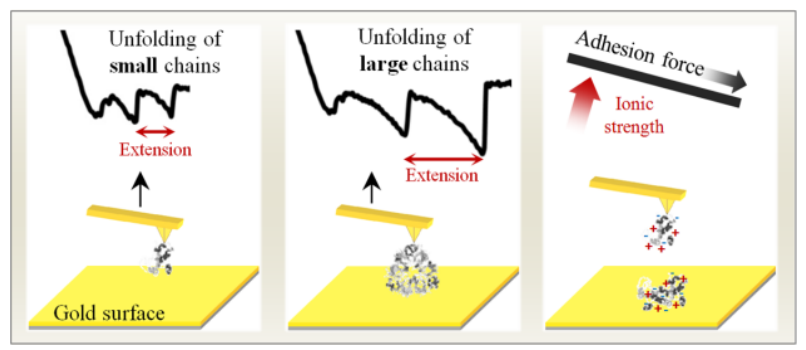

